\title{
Effects of viral infection on photosynthetic processes in the bloom-forming alga Heterosigma akashiwo
}

\author{
Philippe Juneau $^{1, *}$, Janice E. Lawrence ${ }^{1}$, Curtis A. Suttle ${ }^{2}$, Paul J. Harrison ${ }^{1}$ \\ ${ }^{1}$ Department of Earth and Ocean Sciences, and ${ }^{2}$ Department of Earth and Ocean Sciences, Botany, and \\ Microbiology/Immunology, University of British Columbia, Vancouver, British Columbia V6T 1Z4, Canada
}

\begin{abstract}
Pulse-amplitude-modulated (PAM) fluorescence is a technique that allows rapid assessment of photosynthetic activity of phytoplankton. This approach was used to evaluate the effect of viral infection on the photosynthesis of Heterosigma akashiwo, a toxic bloom-forming raphidophyte found in coastal waters of Japan and Canada. We found that viral infection caused by a single strand RNA virus (HaRNAV Strain 263) and 2 uncharacterised DNA viruses (Strains WBs1 and OIs1) gradually impaired photosynthetic activity during the lytic cycle and that photosynthetic electron transport was directly affected by viral infection. Photosystem (PS) II quantum yield of the active reaction centre was much less affected than the overall PSII-PSI electron transport. The decrease in the photosynthetic activity of the infected algae promoted the non-photochemical energy dissipation (heat). Furthermore, the lytic cycle of the viruses was of similar duration in darkness as in the light (ca. $100 \mathrm{~h}$ ), and therefore it was not dependent on photophosphorylation. Our study demonstrates that the sensitivity of PAM fluorometry makes it a useful tool for studying viral infection in phytoplankton populations. Moreover, the results have implications for understanding the role of viral infection on the bloom dynamics of $H$. akashiwo by showing that viral replication is not lightdependent. Hence, viral production can occur below the photic zone.
\end{abstract}

KEY WORDS: Viral infection · Photosynthetic activity $\cdot$ PAM chlorophyll fluorescence $\cdot$ Heterosigma akashiwo Resale or republication not permitted without written consent of the publisher

\section{INTRODUCTION}

In marine environments, viruses are omnipresent and are recognised mortality agents of phytoplankton. Consequently, viruses may affect algal blooms, and therefore influence nutrient cycling, algal diversity and species distribution (Fuhrman 1999, Wilhelm \& Suttle 1999, Suttle 2000). However, the interaction of viruses with bloom-forming algae is not well understood. Some reports suggest that viral infection impairs photosynthetic activity and reduces primary productivity in nature (Suttle et al. 1990, Suttle 1992, Hewson et al. 2001a).

There has been growing interest in factors affecting the population dynamics of Heterosigma akashiwo, a toxic raphidophyte responsible for many red tides in the coastal waters of Japan and Canada (Honjo 1993, Taylor \& Haigh 1993). Recently, it has been shown that a number of different viruses infect and cause the lysis of H. akashiwo (Nagasaki \& Yamaguchi 1998, Lawrence et al. 2002, Tai et al. 2003). One might expect that different viruses will affect the host's metabolism in different ways. However, the effect of viral infection on the photosynthetic activity of this ecologically important species has not been studied. Most studies examining photosynthetic alteration of infected phytoplankton have been conducted with cyanobacteria (Adolph \& Haselkorn 1972, Allen \& Hutchison 1976, Teklemariam et al. 1990, Suttle \& Chan 1993), but some studies have been carried out with the marine prasinophyte Micromonas pusilla and the chlorophyte Chlorella (Waters \& Chan 1982, Van 
Etten et al. 1983). In some instances viral infection leads to the immediate suppression of photosynthetic activity (Van Etten et al. 1983), whereas in other cases photosynthesis continues to the point of the complete lysis of the population (Mackenzie \& Haselkorn 1972, Allen \& Hutchison 1976, Suttle \& Chan 1993). Even similar viruses can have very different effects on their hosts. For example, both M. pusilla virus $(\mathrm{MpV})$ and the Chlorella virus (PBCV1) are members of the family Phycodnaviridae, but photosynthesis is altered by infection more quickly in Chlorella than in M. pusilla (Waters \& Chan 1982, Van Etten et al. 1983).

One relatively simple way to determine photosynthetic activity, and thus gain insight into the physiological state of plants, is by chlorophyll a (chl a) fluorescence measurement (Lichtenthaler \& Rinderle 1988, Bolhàr-Nordenkampf et al. 1989). A fraction of the light energy absorbed by plants is re-emitted as chl a fluorescence, a dissipation process that is in competition with non-radiative energy dissipation processes, both photochemical and non-photochemical (for a review see Lavorel \& Etienne 1977). The level of emitted fluorescence is linked to the redox state of the Photosystem II (PSII) primary electron acceptor, $Q_{\mathrm{A}}$ and plastoquinone (PQ) pool. Upon illumination, the fluorescence signal increases rapidly due to the reduction of these electron acceptors. Thereafter, the fluorescence yield decreases, and this quenching in fluorescence can be attributed to photochemical and non-photochemical events. Photosynthetic electron transport induced during illumination creates, across the thylakoid membranes, a $\mathrm{pH}$ gradient needed for the formation of ATP. This membrane energisation and the induction of the xanthophyll cycle cause conformation changes of the light harvesting complexes (LHCs). These structural modifications lead to an increase in thermal dissipation. Hence, upon illumination, the fluorescence signal decreases due to the activation of photosynthetic electron transport and Calvin cycle reactions (photochemical quenching) and heat dissipation (non-photochemical quenching) (Schreiber et al. 1994, Müller et al. 2001).

Pulse-amplitude-modulated (PAM) fluorometry enables the separation of the photochemical and nonphotochemical quenching $\left(Q_{\mathrm{P}}\right.$ and $\left.Q_{\mathrm{N}}\right)$, and the determination of other parameters such as the PSII maximal quantum yield and the PSII operational quantum yield $\left(\phi_{M}\right.$ and $\left.\phi_{M}^{\prime}\right)$, which are useful in evaluating the plant's physiological state. Using these parameters, it is possible to gain information on the capacity of dark-adapted $\left(\phi_{\mathrm{M}}\right)$ and light-adapted $\left(\phi_{\mathrm{M}}^{\prime}\right)$ plants to convert light energy into chemical energy (Bolhàr-Nordenkampf et al. 1989, Genty et al. 1989). Furthermore, $Q_{\mathrm{P}}$ and $Q_{\mathrm{N}}$ are effective indicators of the photosynthetic energy conversion processes (Schreiber et al. 1986, Seaton \&
Walker 1992, Buschmann 1995). $Q_{\mathrm{P}}$ represents the proportion of light energy used for electron transport, while $Q_{\mathrm{N}}$ represents the thermal dissipation of light energy and can be divided into 3 components: energydependent, state-transition and photoinhibitory quenching (for a complete review see Müller et al. 2001).

Chl a fluorescence was first used to monitor changes in photosynthetic activity induced by viral infection in plants infected with tobacco mosaic virus and peanut green mosaic virus (Naidu et al. 1984, Hodgson et al. 1989). Thereafter, some studies were conducted using PAM fluorometry to study the effect of viral infection in algae (Seaton et al. 1996, Hewson et al. 2001a,b).

The aim of our study was to examine the time course of viral infection with a single strand RNA virus (HaRNAV Strain 263) and 2 uncharacterised DNA viruses (isolates WBs1 and OIs1) on the photosynthetic activity of Heterosigma akashiwo, and to determine the dependence of viral replication on photosynthesis.

\section{MATERIALS AND METHODS}

Culture conditions. Heterosigma akashiwo (NEPCC 522), originally isolated from English Bay, Vancouver, Canada, and Micromonas pusilla strain Plymouth 27 (UTEX 991) were used for all experiments. Cultures were maintained in $\mathrm{f} / 2$-enriched seawater (Guillard 1975) (30 ppt salinity) supplemented with $10 \mathrm{nM}$ sodium selenite under continuous illumination of $260 \mu \mathrm{mol} \mathrm{m}{ }^{-2} \mathrm{~s}^{-1}$ photosynthetically active radiation, at $20^{\circ} \mathrm{C}$. Growth was estimated by directly measuring in vivo chl a fluorescence (Turner Designs fluorometer) and/or cell number (Coulter Z2 particle count and size analyser) over time. Cultures for PAM fluorometry experiments were grown in 50 or $6.5 \mathrm{ml}$ borosilicate culture tubes, depending on the volume of culture required for the experiment.

HaRNAV (clone 263) was used in these experiments, as described by Tai et al. (2003). The DNA virus clones WBs1 and OIs1 were obtained from sediment samples described in Lawrence et al. (2002). These viruses were cloned by diluting each virus to extinction twice (Cottrell \& Suttle 1991). Virus stocks of all clones were produced by adding $0.1 \%(\mathrm{v} / \mathrm{v})$ culture lysate to exponentially growing non-axenic Heterosigma akashiwo cultures and monitoring for lysis by in vivo fluorescence. Lysates were filtered through glass-fibre filters (Micro Filtration Systems GC50, nominal pore size = $1.2 \mu \mathrm{m}$ ) and polyvinylidine difluoride filters (Millipore, Durapore, $0.45 \mu \mathrm{m}$ pore size), and stored at $4^{\circ} \mathrm{C}$ until use. The virus (MpV-SP1) used for the infection of Micromonas pusilla was described by Cottrell \& Suttle (1991). 
Exponentially growing cultures of Heterosigma akashiwo or Micromonas pusilla were inoculated with 0.1 or $1 \%(\mathrm{v} / \mathrm{v})$ lysate respectively, and incubated under the growth conditions described above. Inoculation with higher concentrations of virus did not decrease the lengths of the lytic cycles (Lawrence unpubl. data). Therefore, we are confident that these concentrations are sufficient to saturate the cultures and that all cells were infected at the beginning of the experiment. Growth was monitored by in vivo fluorescence and/or cell counts. To examine the lytic cycle under complete darkness, exponentially growing cultures of $H$. akashiwo were inoculated with $0.1 \%(\mathrm{v} / \mathrm{v})$ lysate and divided into 2 treatments. One set of tubes was incubated under the conditions described above, while another set was wrapped in 2 layers of aluminium foil to achieve complete darkness, and incubated in the same way. Culture growth and lysis were monitored by destructively sampling culture tubes to measure in vivo fluorescence.

Transmission electron microscopy (TEM). Thin sections of infected Heterosigma akashiwo were prepared for TEM according to Lawrence et al. (2001). Sections were viewed with a Zeiss 10C-TEM at an accelerating voltage of $80 \mathrm{kV}$.

PAM fluorescence measurements. Fluorescence induction measurements were taken with a PAM 101/103 fluorometer equipped with an ED-101PM emitter-detector-cuvette unit (Walz) after dark-acclimation of the algae for 25 min (Schreiber et al. 1986). The constant fluorescence of dark-adapted algae $\left(F_{0}\right)$ was measured by using modulated light (US-L655, Walz) having a very low intensity (ca. $5 \mu \mathrm{mol} \mathrm{m}^{-2} \mathrm{~s}^{-1}$ ) to avoid reduction of the PSII primary electron acceptor $Q_{\mathrm{A}}$. The maximal fluorescence yield $\left(F_{\mathrm{m}}\right)$ was induced by a short (50 or $700 \mathrm{~ms}$ ) saturating pulse of light (5000 or $3000 \mu \mathrm{mol} \mathrm{m}^{-2} \mathrm{~s}^{-1}$ respectively), which triggered the reduction of all $Q_{\mathrm{A}}$ and $\mathrm{PQ}$ pool. No significant difference was observed between these flash intensities. The flash intensities were saturating as the addition of DCMU, which blocks electron transport at the PSII secondary electron acceptor $Q_{\mathrm{B}}$ and induces maximal fluorescence, did not result in further increases in fluorescence (data not shown). The induction of electron transport was triggered by a continuous actinic white light $\left(50 \mu \mathrm{mol} \mathrm{m}{ }^{-2} \mathrm{~s}^{-1}, \mathrm{KL}-1500\right.$ FL103, Walz). Every $30 \mathrm{~s}, 50$ or $700 \mathrm{~ms}$ saturating flashes were applied with an intensity of approximately 5000 and $3000 \mu \mathrm{mol} \mathrm{m}^{-2}$ $\mathrm{s}^{-1}$ respectively. No significant difference was observed between the fluorescence yields induced by these 2 flash intensities. The different fluorescence parameters were calculated as described in Juneau et al. (2002), after subtraction of the blank fluorescence value, with home-made software. Unless otherwise mentioned, triplicate samples were taken and analysed using a 1-way analysis of variance (ANOVA).

\section{RESULTS}

The initial decline in biomass of cells infected with HaRNAV was observed before cultures infected with WBs1 or OIs1 (36 vs $48 \mathrm{~h}$ ), whether measured by relative fluorescence (Fig. 1A) or cell number (Fig. 1B). However, complete lysis occurred at approximately $100 \mathrm{~h}$ for the 3 viruses.

Photosynthesis was also altered by viral infection concomitant with the biomass decrease. The $\phi_{\mathrm{M}}$ of Heterosigma akashiwo infected with HaRNAV decreased by ca. $10 \%$ within $36 \mathrm{~h}$ and changed only slightly thereafter (Fig. 2A). In contrast, infection with WBs1 or OIs1 caused $\phi_{\mathrm{M}}$ to decrease by ca. 10 and $35 \%$ after 36 and $96 \mathrm{~h}$ respectively (Figs. 3A \& 4A). Fluorescence parameters obtained when electron transport was at steady-state $\left(\phi_{M}^{\prime}, Q_{\mathrm{P}}, Q_{\mathrm{N}}\right)$ were more affected by viral infection than $\phi_{M}$ (Figs. 2 to 4). Thus, after $96 \mathrm{~h} \phi_{M}^{\prime}$ decreased by approximately 55,65 and $75 \%$ compared to the controls for HaRNAV, WBs1 and OIs1 respectively. $Q_{\mathrm{P}}$ was less affected than $\phi_{\mathrm{M}}^{\prime}$, decreasing by 20 ,

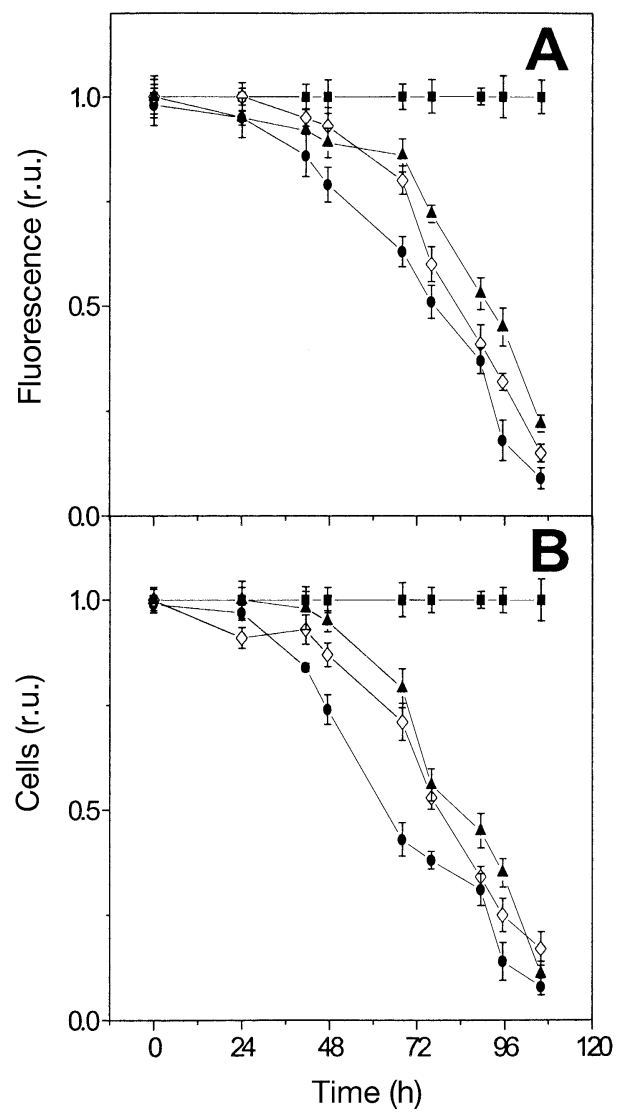

Fig. 1. Heterosigma akashiwo. Biomass measured by (A) relative fluorescence and (B) cell numbers of algae infected with the viruses HaRNAV $(\bullet)$, WBs1 $(\boldsymbol{\bullet})$, and OIs1 $(\diamond)$ compared to an uninfected control ( $\bullet$ ). Error bars $= \pm 1$ SD, $\mathrm{n}=3$ or 4 . r.u.: relative units 


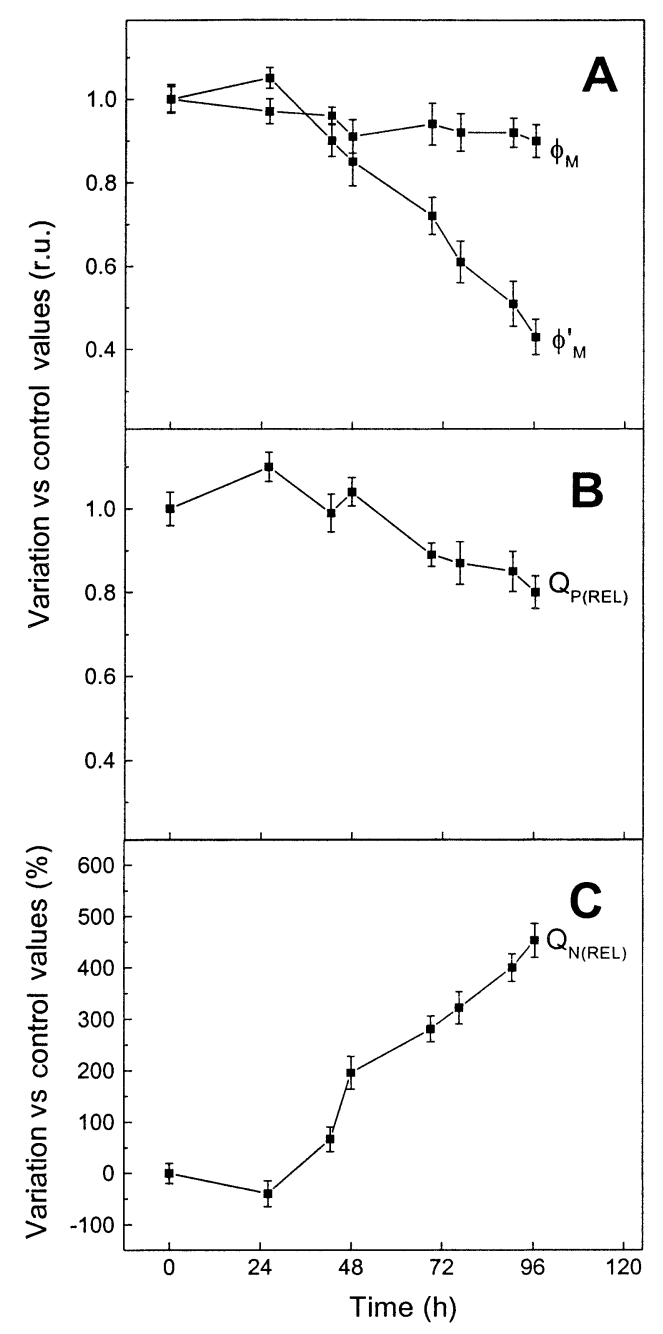

Fig. 2. Heterosigma akashiwo. Variation (\%) in 4 fluorescence parameter values during the lytic cycle of algae infected with HaRNAV compared to the control: (A) maximal PSII quantum yield $\left(\phi_{\mathrm{M}}\right)$ and operational PSII quantum yield $\left(\phi_{\mathrm{M}}^{\prime}\right),(\mathrm{B})$ photochemical quenching $\left(Q_{\mathrm{P}}\right)$, and $(\mathrm{C})$ non-photochemical quenching $\left(Q_{\mathrm{N}}\right)$. Error bars $= \pm 1 \mathrm{SD}, \mathrm{n}=3$ or 4 . r.u.: relative units

35 and $50 \%$ for HaRNAV, WBs1 and OIs1 respectively. As expected, when photochemistry was impaired, $Q_{\mathrm{N}}$ values were drastically altered in infected cells, and they increased by up to $500 \%$ compared to the controls. A similar pattern was also seen when Micromonas pusilla cells were infected by $\mathrm{MpV}_{\text {; however, }}$ the effect on photosynthesis was seen earlier than the effect on biomass (data not shown).

Table 1 shows the variation over time in constant $\left(F_{\mathrm{o}}\right)$ and maximal $\left(F_{\mathrm{m}}\right)$ fluorescence normalised per cell for Heterosigma akashiwo infected with the different viruses, relative to uninfected controls. OIs1 and WBs1 induced a gradual increase in $F_{0}$ :cell ratio during the infection. Normalised $F_{\mathrm{o}}$ levels of cells infected with HaRNAV were relatively constant and similar to the control up to $48 \mathrm{~h}$, but after $48 \mathrm{~h}$, viral infection caused a drastic increase in this ratio. On the other hand, normalised $F_{\mathrm{m}}$ decreased in $H$. akashiwo infected with the OIs1 and WBs1 viruses, but the amplitude of the changes was smaller than for $F_{\mathrm{o}}$ variations. For HaRNAV, $F_{\mathrm{m}}$ :cell ratio increased by $28 \%$ compared to the control. Viral infection did not induce obvious changes in chloroplast organisation before the lysis of infected $H$. akashiwo cells (data not shown). Indeed, chloroplasts stayed intact during the entire lytic cycle, even when the cells started to degrade.

In order to determine if the viruses directly affect the electron transport chain, the effect of methyl viologen (MV), a PSI electron acceptor that will restore photochemistry if the damage site is located beyond the PSI,

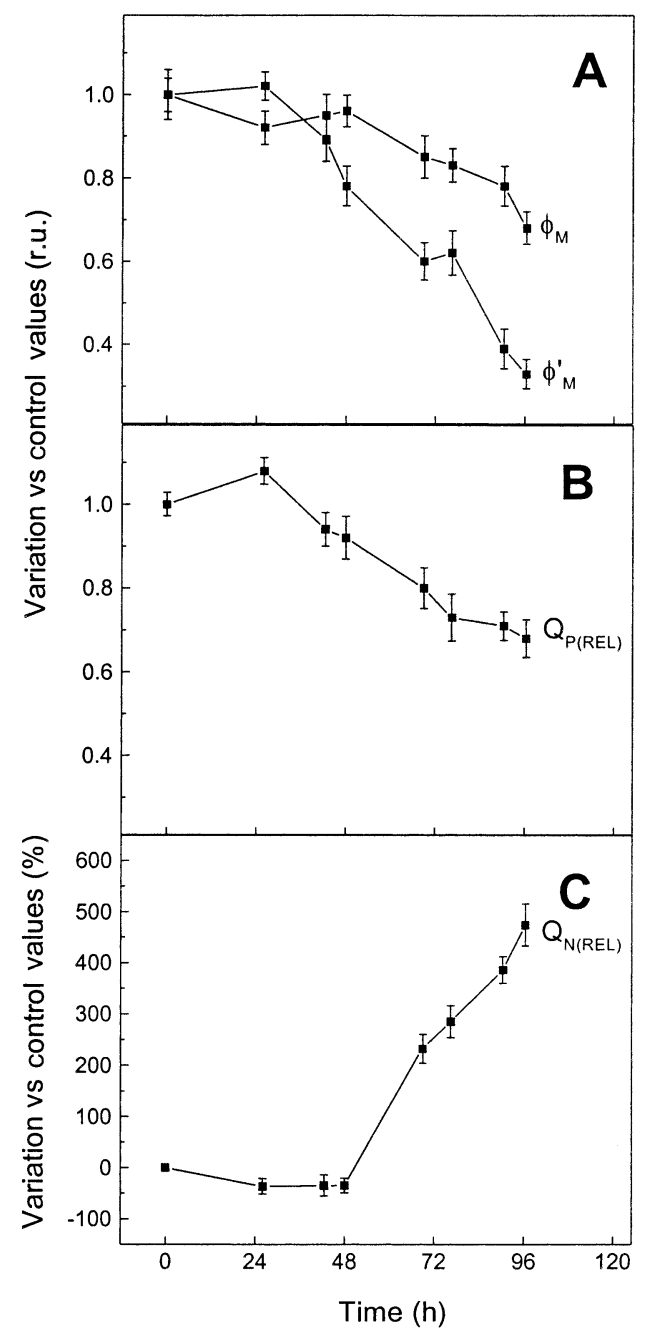

Fig. 3. Heterosigma akashiwo. Variation (\%) in 4 fluorescence parameter values during the lytic cycle of algae infected with WBs1 compared to the control: (A) maximal PSII quantum yield $\left(\phi_{M}\right)$ and operational PSII quantum yield $\left(\phi_{M}^{\prime}\right),(B)$ photochemical quenching $\left(Q_{\mathrm{P}}\right)$, and $(\mathrm{C})$ non-photochemical quenching $\left(Q_{\mathrm{N}}\right)$. Error bars $= \pm 1 \mathrm{SD}, \mathrm{n}=3$ or 4 . r.u.: relative units 
Table 1. Heterosigma akashiwo. Variation of the constant fluorescence of dark-adapted algae $F_{\mathrm{o}}$ :cell and the maximal fluorescence yield $F_{\mathrm{m}}$ :cell ratios as \% of control $( \pm 1 \mathrm{SD}, \mathrm{n}=3$ or 4) in cultures infected with 3 different viruses

\begin{tabular}{|cccccc|}
\hline Virus & $0 \mathrm{~h}$ & $24 \mathrm{~h}$ & $48 \mathrm{~h}$ & $72 \mathrm{~h}$ & $96 \mathrm{~h}$ \\
\hline HaRNAV & & & & \\
$F_{\mathrm{o}}$ & $0(3.1)$ & $-2.6(4.0)$ & $-0.4(3.9)$ & $55.3(4.3)$ & \\
$F_{\mathrm{m}}$ & $0(1.4)$ & $0.8(2.1)$ & $-3.4(3.1)$ & $27.5(2.7)$ & \\
WBs1 & & & & & \\
$F_{\mathrm{o}}$ & $1(2.5)$ & $-6.8(3.2)$ & $5.1(3.5)$ & $15.4(2.9)$ & $29.5(4.1)$ \\
$F_{\mathrm{m}}$ & $0(2.1)$ & $-6.3(1.9)$ & $2.2(2.3)$ & $-8.8(1.5)$ & $-23.6(3.5)$ \\
OIs1 & & & & & \\
$F_{\mathrm{o}}$ & $0(4.1)$ & $2.5(4.1)$ & $14.2(2.4)$ & $36.9(3.2)$ & \\
$F_{\mathrm{m}}$ & $2(1.4)$ & $1.8(2.7)$ & $-8.3(1.9)$ & $-18.3(2.8)$ & \\
\hline
\end{tabular}

was evaluated when $\phi^{\prime}{ }_{M}$ was inhibited 45 to $55 \%$ by viral infection. As shown for the non-infected cells, MV did not significantly $(\mathrm{p}>0.05)$ affect $\phi_{\mathrm{M}}, \phi_{\mathrm{M}}^{\prime}$ and $Q_{\mathrm{P}}$, but tended to increase $Q_{\mathrm{N}}$ (Table 2). The increase in $Q_{\mathrm{N}}$ is in agreement with previous studies where MV increased the proton gradient across the thylakoid membranes in higher plants (Salvucci et al. 1987). For cells infected with HaRNAV, as for the control, no significant variation in the photochemical parameters was observed in the presence of MV. While $Q_{\mathrm{N}}$ increased in non-infected algae, it increased an additional $20 \%$ in algae infected with HaRNAV. For Heterosigma akashiwo infected with WBs1 and OIs1, we observed a significant $(p<0.05)$ decrease in $\phi_{M}$ and $\phi_{M}^{\prime}$. As with cells infected with HaRNAV, cells infected with WBs1 and OIs1 showed a significant $(p<0.05)$ increase in $Q_{\mathrm{N}}$. The increase in $Q_{\mathrm{N}}$ reached $96 \%$ in cells infected by OIs1 compared to $43 \%$ for the non-infected cells.

To further investigate the relationship between viral infection and photosynthetic processes, we also conducted infections when photosynthetic electron transport was completely inhibited (darkness). Cell lysis, which was associated with a rapid decrease in the

Table 2. Heterosigma akashiwo. Variation of PS II maximal $\left(\phi_{\mathrm{M}}\right)$ and operational $\left(\phi_{\mathrm{M}}^{\prime}\right)$ quantum yield and photochemical $\left(Q_{\mathrm{P}}\right)$ and non-photochemical $\left(Q_{\mathrm{N}}\right)$ quenching $( \pm 1 \mathrm{SD}, \mathrm{n}=3)$ in the presence of $0.5 \mathrm{mM}$ methyl viologen (MV) for infected algae having 45 to $55 \%$ of photosynthetic activity relative to uninfected controls

\begin{tabular}{|lrrrr|}
\hline \multicolumn{4}{|c|}{ Variation as \% of non-MV-treated algae } \\
& $\phi_{\mathrm{M}}$ & \multicolumn{1}{c|}{$\phi_{\mathrm{M}}^{\prime}$} & \multicolumn{1}{c|}{$Q_{\mathrm{P}}$} & \multicolumn{1}{c}{$Q_{\mathrm{N}}$} \\
\hline Control + MV & $1.9(2.5)$ & $6.0(2.7)$ & $6.9(3.0)$ & $43(2.9)$ \\
HaRNAV + MV & $-4.3(2.1)$ & $2.8(3.2)$ & $6.0(2.2)$ & $64(4.1)$ \\
WBs1 + MV & $-15(4.1)$ & $-10(2.1)$ & $-4.1(1.9)$ & $76(4.4)$ \\
OIs1 + MV & $-32(3.7)$ & $-13(2.7)$ & $-2.8(2.4)$ & $96(4.9)$ \\
\hline
\end{tabular}

fluorescence relative to the control, occurred at the same time after infection in the light or dark for all 3 viruses (data not shown), indicating that lysis is possible in the dark for Heterosigma akashiwo.

\section{DISCUSSION}

\section{Alteration of photosynthetic processes}

Our work clearly shows that photosynthetic activity in Heterosigma akashiwo was impaired by viral infection. The effects of infection on photosynthesis were similar for the 3 viruses, although they occurred at different times. Viral infection inhibits photosynthesis

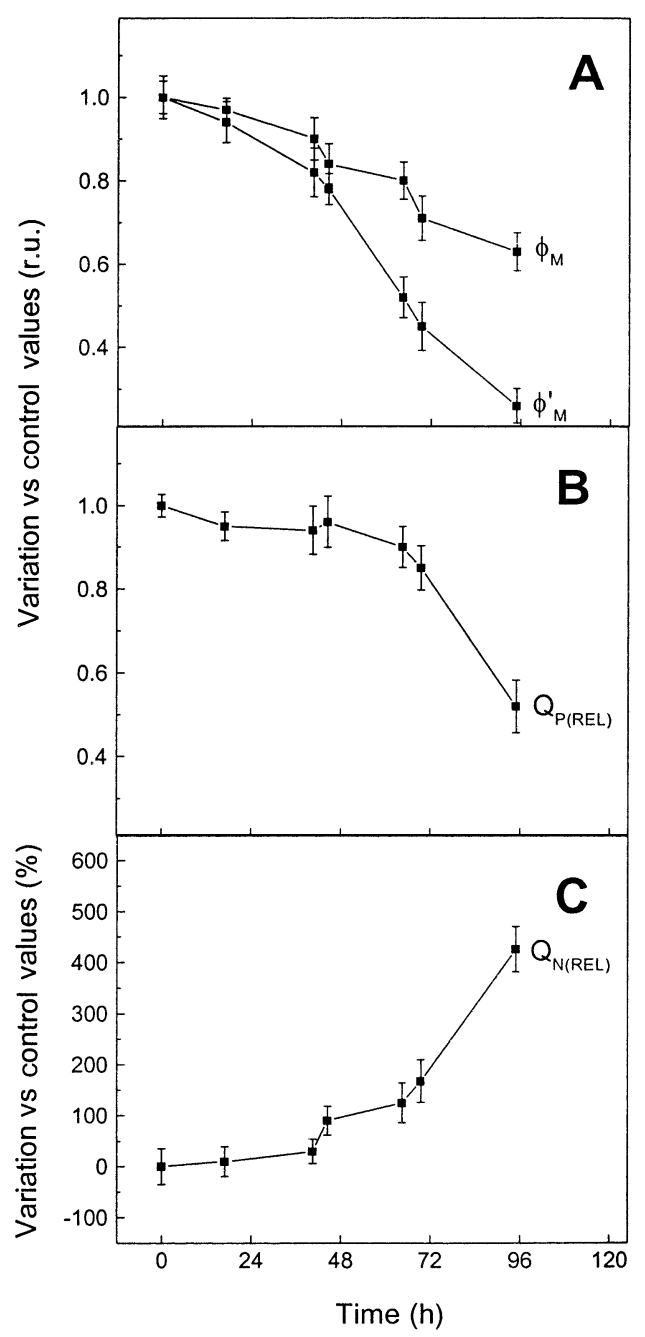

Fig. 4 Heterosigma akashiwo. Variation (\%) in 4 fluorescence parameter values during the lytic cycle of algae infected with OIs1 compared to the control: (A) maximal PSII quantum yield $\left(\phi_{\mathrm{M}}\right)$ and operational PSII quantum yield $\left(\phi_{M}^{\prime}\right),(\mathrm{B})$ photochemical quenching $\left(Q_{\mathrm{P}}\right)$, and $(\mathrm{C})$ non-photochemical quenching

$\left(Q_{\mathrm{N}}\right)$. Error bars $= \pm 1 \mathrm{SD}, \mathrm{n}=3$ or 4 . r.u.: relative units 
almost immediately after infection of Chlorellainfected cells (Van Etten et al. 1983). However, in other algal-virus systems, such as Anacystis nidulans and Synechococcus spp., photosynthesis continues unabated prior to cell lysis and viral development is highly dependent on host photosynthesis (Mackenzie \& Haselkorn 1972, Allen \& Hutchison 1976, Suttle \& Chan 1993). In contrast, in Micromonas pusilla and Synechococcus sp. PCC 6301, photosynthetic activity of the host decreased gradually following infection (Waters \& Chan 1982, Teklemariam et al. 1990). Similarly, the overall photosynthetic activity, as shown by $\phi_{M}^{\prime}$ and $Q_{\mathrm{P}}$, also gradually decreased following viral infection of $H$. akashiwo. Even though the overall PSIIPSI electron transport was strongly altered in $H$. akashiwo, $\phi_{\mathrm{M}}$ was only affected slightly for cells infected with HaRNAV. However, the effect of WBs1 and OIs1 on $\phi_{M}$ was more pronounced (see Figs. 2 to 4 ).

The steady-state fluorescence parameters $\left(\phi^{\prime}{ }_{M}\right.$ and $Q_{\mathrm{P}}$ ) demonstrated a strong influence of viruses on the overall PSII-PSI electron transport. This alteration could be indirect as was demonstrated in Paramecium bursaria Chlorella virus-1 (PBCV1) and transgenic tobacco plants (Seaton et al. 1995, 1996, Wolf \& Millatiner 2000). In those experiments, the addition of an exogenous PSI electron acceptor, MV, restored the photochemical activity when electron transport was at steady-state. In contrast, a direct alteration of the PSIIPSI electron transport was shown in some higher plant systems (Hodgson et al. 1989, van Kooten et al. 1990, Rahoutei et al. 2000), where a destruction of the PSIIPSI related electron carriers occurred. Our results are consistent with the damage of the PSII-PSI electron transport chain following infection because the photosynthetic activity of $H$. akashiwo was not restored by MV.

Concomitant to the decrease in photosynthetic activity, non-photochemical energy dissipation processes $\left(Q_{\mathrm{N}}\right)$ increased drastically, suggesting that heat dissipation is the main energy dissipation process in infected algae. This indicates that when the photochemistry begins to be affected (36 to $48 \mathrm{~h}$ ), Heterosigma akashiwo develops a mechanism to prevent further damage to its photosynthetic apparatus by excess light, by increasing non-photochemical energy dissipation. This process is known to prevent photoinhibition (Horton et al. 1996). The further increase in the $Q_{\mathrm{N}}$ in the presence of $\mathrm{MV}$, when 45 to $55 \%$ of electron transport is still occurring, may be due to MV mediation of pseudo-cyclic electron transport (Mehler reaction). The reduction of $\mathrm{O}_{2}$ mediated by $\mathrm{MV}$ will therefore decrease the production of $\mathrm{NADPH}$; also the $\mathrm{CO}_{2}$ fixation may be decreased in the presence of $\mathrm{MV}$ (Salvucci et al. 1987). Consequently, the ATP consumption is diminished and we may suppose that the pseudo-cyclic electron flow is favoured compared to the linear one. This would generate a higher proton gradient and therefore a higher $Q_{\mathrm{N}}$ (Schreiber \& Neubauer 1990). The strong $Q_{\mathrm{N}}$ induced by MV in $H$. akashiwo infected with WBs1 and OIs1 may also be responsible for the observed decrease in PSII quantum yield (Wilhelm \& Duval 1990).

\section{Effects on chloroplast morphology and photosynthetic apparatus integrity}

Chloroplasts of infected cells remained relatively intact until cell lysis (data not shown). However, since the constant fluorescence per cell increased upon infection, we surmise that molecular changes in the conformation of the light harvesting complexes (LHCs) and/or degradation of the PSII reaction centres occurred during the infection cycle. The increase cannot be linked to a higher chlorophyll concentration per cell since we demonstrated that cell number and fluorescence co-vary during the lytic cycle (Fig. 1). An increase in constant fluorescence was previously noticed in stressed plant systems, such as heated leaves and Fe-limited algae (Naus et al. 1992, Belkhodja et al. 1998). Among other factors, it has been suggested that an increase in $F_{o}$ may be caused by an alteration of electron transport in PSII reaction centres (Schreiber \& Armond 1978) and/or by a disconnection of LHCs from PSII (Yamane et al. 1997). Since the activity of the PSII reaction centres was preserved to some extent (i.e. $\phi_{\mathrm{M}}$ was not greatly affected), it is more likely that viral infection caused a disconnection of the LHCs from PSII. The variation in $F_{\mathrm{m}}$ :cell ratio observed in infected cells may be due to the disconnection of the LHCs from PSII reaction centres, but also from an alteration of the reaction centres. We might explain the increase in $F_{\mathrm{m}}$ level for HaRNAV by the fact that $F_{\mathrm{o}}$ increase was very important $(55 \%)$, therefore artificially increasing the $F_{\mathrm{m}}$ level. One might also expect that the increase in $F_{\mathrm{o}}$ is due to the fact that a part of $Q_{\mathrm{A}}$ and the PQ pool cannot be reoxidised during dark adaptation because of the alteration of PSII-PSI electron transport carriers by viral infection (Bukhov et al. 1992). Further work is needed in order to obtain a precise explanation of those changes at the molecular level.

\section{Viral replication energy source}

Using $\mathrm{CO}_{2}$ fixation, Waters \& Chan (1982) showed that photosynthesis in Micromonas pusilla decreased gradually upon infection, similar to Heterosigma akashiwo, although in M. pusilla the effect on photosyn- 
thesis was seen earlier in the lytic cycle than the effect on biomass. To determine if the observed difference between $M$. pusilla and $H$. akashiwo is due to the mode of action of the viruses, we performed the same experiment with $M$. pusilla and monitored photosynthetic activity with PAM fluorometry. We found that the effect of viral infection on photosynthesis was also seen earlier than the effect on biomass in M. pusilla. Therefore, the difference in the effects on photosynthesis and biomass between $M$. pusilla and $H$. akashiwo is due to a variation in the mode of action of the viruses.

Since photosynthesis is shut down gradually and is not inhibited immediately after the attachment of the virus to the alga, as it occurs in Chlorella-PBCV-1 (Van Etten et al. 1983), this suggests that viral replication in Heterosigma akashiwo requires energy produced by photosynthetic electron transport. However, culture lysis also occurred in the dark, when linear electron transport does not occur, and the length of the lytic cycle in the dark was similar to that under normal growth conditions (light:dark cycle). In contrast, previous studies conducted with cyanobacteria demonstrated that photosynthesis was required for completion of the lytic cycle (Mackenzie \& Haselkorn 1972, Allen \& Hutchison 1976). Given that viral replication was not dependent on photosynthetic electron transport, the question arises as to the source of energy for viral replication in $H$. akashiwo. It is possible that viral replication in $H$. akashiwo uses energy produced by chlororespiration, a mechanism that can occur in darkness (Bennoun 1982, Peltier \& Schmidt 1991). Viral replication could also be supported by ATP reserves and/or production via respiration as demonstrated in Plectonema boryanum and Nostoc muscorum (Sherman \& Haselkorn 1971, Adolph \& Haselkorn 1972). We may hypothesise that, in our experiments, the occurrence of the complete lysis of the population in darkness for $H$. akashiwo may have been the result of the high reserve of phosphate found in $H$. akashiwo (Watanabe et al. 1987, 1988), which may regulate the level of ATP (Rubtsov \& Kulaev 1977).

\section{Conclusions and implications}

By using PAM fluorometry, our study showed that the PSII-PSI electron transport in Heterosigma akashiwo was directly affected by viral infection, and that the effect on photosynthesis was dependent on the viral strain. Furthermore, we showed that photosynthesis was not actively required for viral replication. Since viral replication can occur in darkness, our data suggest that viral replication may also occur below the euphotic zone and in sediments. These results have implications for understanding the role of light and photosynthesis on viral replication in this toxic bloomforming alga. Ultimately, since PAM fluorometry offers the advantages of simplicity and rapidity, we expect that it will be useful for studying the role of viral infection in phytoplankton bloom dynamics in natural environments, as was demonstrated recently for benthic microalgae (Hewson et al. 2001b).

Acknowledgements. This research was supported by Natural Sciences and Engineering Research Council of Canada (NSERC) Research Grants to C.A.S. and P.J.H. P.J. and J.E.L. received support from NSERC Postdoctoral Fellowships.

\section{LITERATURE CITED}

Adolph KW, Haselkorn R (1972) Photosynthesis and the development of blue-green algal virus N-1. Virology 47: 370-374

Allen MM, Hutchison F (1976) Effect of some environmental factors on cyanophage AS-1 development in Anacystis nidulans. Arch Microbiol 110:55-60

Belkhodja R, Morales F, Quílez R, López-Millán AF, Abadía A, Abadía J (1998) Iron deficiency causes changes in chlorophyll fluorescence due to the reduction in the dark of the Photosystem II acceptor side. Photosynth Res 56: 265-276

Bennoun P (1982) Evidence for a respiratory chain in the chloroplast. Proc Natl Acad Sci USA 79:4352-4356

Bolhàr-Nordenkampf HR, Long SP, Baker NR, Öquist G, Schreiber U, Lechner EG (1989) Chlorophyll fluorescence as a probe of the photosynthetic competence of leaves in the field: a review of current instrumentation. Funct Ecol 3:497-514

Bukhov NG, Mohanty P, Rakhimberdieva MG, Karapetyan V (1992) Analysis of dark-relaxation kinetics of variable fluorescence in intact leaves. Planta 187:122-127

Buschmann C (1995) Variation of the quenching of chlorophyll fluorescence under different intensities of the actinic light in wildtype plants of tobacco and in an Aurea mutant deficient of light-harvesting-complex. J Plant Physiol 145: $245-252$

Cottrell MT, Suttle CA (1991) Wide-spread occurence and clonal variation in viruses which cause lysis of a cosmopolitan, eukaryotic marine phytoplankter, Micromonas pusilla. Mar Ecol Prog Ser 78:1-9

Fuhrman JA (1999) Marine viruses and their biogeochemical and ecological effects. Nature 399:541-548

Genty B, Briantais JM, Baker NR (1989) The relationship between the quantum yield of photosynthetic electron transport and quenching of chlorophyll fluorescence. Biochim Biophys Acta 990:87-92

Guillard RRL (1975) Culture of phytoplankton for feeding marine invertebrates. In: Smith WL, Chanley MH (eds) Culture of marine invertebrate animals. Plenum Press, New York, p 29-60

Hewson I, O'Neil JM, Dennison WC (2001a) Virus-like particles associated with Lyngbya majuscula (Cyanophyta; Oscillatoriacea) bloom decline in Moreton Bay, Australia. Aquat Microb Ecol 25:207-213

Hewson I, O'Neil JM, Heil CA, Bratbak G, Dennison WC (2001b) Effects of concentrated viral communities on photosynthesis and community composition of co-occur- 
ring benthic microalgae and phytoplankton. Aquat Microb Ecol 25:1-10

Hodgson RAJ, Beachy RN, Pakrasi HB (1989) Selective inhibition of photosystem II in spinach by tobacco mosaic virus: an effect of the viral coat protein. FEBS Lett 245: $267-270$

Honjo T (1993) Overview on bloom dynamics and physiological ecology of Heterosigma akashiwo. In: Smayda TJ, Shimizu Y (eds) Toxic phytoplankton blooms in the sea. Elsevier Science Publishers, Amsterdam, p 33-41

Horton P, Ruban AV, Walters RG (1996) Regulation of light harvesting in green plants. Annu Rev Plant Physiol Plant Mol Biol 47:655-684

Juneau P, El Berdey A, Popovic R (2002) PAM-fluorometry in the determination of the sensitivity of Chlorella vulgaris, Selenatrum capricornutum and Chlamydomonas reinhardtii to copper. Arch Environ Contam Toxicol 42: 155-164

Lavorel J, Etienne AL (1977) In vivo chlorophyll fluorescence. In: Barber J (ed) Primary processes of photosynthesis. Elsevier/North-Holland Biomedical Press, Amsterdam, p 203-268

Lawrence JE, Chan AM, Suttle CA (2001) A novel virus (HaNIV) causes lysis of the toxic bloom-forming alga Heterosigma akashiwo (Raphidophyceae). J Phycol 37 : 216-222

Lawrence JE, Chan AM, Suttle CA (2002) Viruses causing lysis of the toxic bloom-forming alga Heterosigma akashiwo (Raphidophyceae) are widespread in coastal sediments of British Columbia, Canada. Limnol Oceanogr 47:545-550

Lichtenthaler HK, Rinderle U (1988) The role of chlorophyll fluorescence in the detection of stress conditions in plants. Crit Rev Anal Chem 19:29-85

Mackenzie JJ, Haselkorn R (1972) Photosynthesis and the development of blue-green algal virus SM-1. Virology 49: 517-521

Müller P, Li XP, Niyogi K (2001) Non-photochemical quenching: a response to excess light energy. Plant Physiol 125: 1558-1566

Nagasaki K, Yamaguchi M (1998) Intra-species host specificity of HaV (Heterosigma akashiwo virus) clones. Aquat Microb Ecol 14:109-112

Naidu RA, Krishnan M, Ramanujan P, Gnaman A, Nayuda MV (1984) Studies on peanut green mosaic virus infected peanut (Arachis hypogaea L.) leaves. I. Photosynthesis and photochemical reactions. Physiol Plant Pathol 25:181-190

Naus J, Kuropatwa R, Klinkovskÿ T, Ilík P, Lattova J, Pavlová $\mathrm{Z}$ (1992) Heat injury of barley leaves detected by the chlorophyll fluorescence temperature curve. Biochim Biophys Acta 1101:359-362

Peltier G, Schmidt GW (1991) Chlororespiration: an adaptation to nitrogen deficiency in Chlamydomonas reinhartii. Proc Natl Acad Sci USA 88:4791-4795

Rahoutei J, García-Luque I, Barón M (2000) Inhibition of photosynthesis by viral infection: effect on PSII structure and function. Physiol Plant 110:286-292

Rubtsov PM, Kulaev IS (1977) Some pathways of polyphosphate biosynthesis and degradation in Acetabularia mediterranea. Biochemistry (translated from Biokhimiya) 42: 843-848

Salvucci ME, Portis AR JR, Heber U, Ogren WL (1987) Stimulation of thylakoid energization and ribulosebisphosphate carboxylase/oxygenase activation in Arabidopsis leaves by methyl viologen. FEBS Lett 221: 215-220

Schreiber U, Armond PA (1978) Heat-induced changes of chlorophyll fluorescence in isolated chloroplasts and related heat-damage at the pigment level. Biochim Biophys Acta 502:138-151

Schreiber U, Neubauer C (1990) $\mathrm{O}_{2}$-dependent electron flow, membrane energization and the mechanism of non-photochemical quenching of chlorophyll fluorescence. Photosynth Res 25:279-293

Schreiber U, Schliwa U, Bilger W (1986) Continuous recording of photochemical and non-photochemical chlorophyll fluorescence quenching with a new type of modulation fluorometer. Photosynth Res 10:51-62

Schreiber U, Bilger W, Neubauer C (1994) Chlorophyll fluorescence as a nonintrusive indicator for rapid assessment of in vivo photosynthesis. In: Schulze ED, Caldwell MM (eds) Ecophysiology of photosynthesis.: ecological studies. Springer-Verlag, Berlin, p 49-70

Seaton GGR, Walker DA (1992) Validating chlorophyll fluorescence measures of efficiency: observations on fluorimetric estimation of photosynthetic rate. Proc R Soc Lond B 249:41-47

Seaton GGR, Lee K, Rohozinski J (1995) Photosynthetic shutdown in Chlorella NC64A associated with the infection cycle of Paramecium bursaria Chlorella virus-1. Plant Physiol 108:1431-1438

Seaton GGR, Hurry VM, Rohozinski J (1996) Novel amplification of non-photochemical chlorophyll fluorescence quenching following viral infection in Chlorella. FEBS Lett 389:319-323

Sherman LA, Haselkorn R (1971) Growth of the blue-green algae virus LPP-1 under conditions which impair photosynthesis. Virology 45:739-746

Suttle CA (1992) Inhibition of photosynthesis in phytoplankton by submicron size fraction concentrated from seawater. Mar Ecol Prog Ser 87:105-112

Suttle CA (2000) Ecological, evolutionary, and geochemical consequences of viral infection of cyanobacteria and eukaryotic algae. In: Hurst CJ (ed) Viral ecology. Academic Press, London, p 247-296

Suttle CA, Chan AM (1993) Marine cyanophages infecting oceanic and coastal strains of Synechococcus: abundance, morphology, cross-infectivity and growth characteristics. Mar Ecol Prog Ser 92:99-109

Suttle CA, Chan AM, Cottrell MT (1990) Infection of phytoplankton by viruses and reduction of primary productivity. Nature 347:467-469

Tai V, Lawrence JE, Suttle CA (2003) Characterization of HaRNAV, a novel single-stranded RNA virus causing lysis of the toxic bloom-forming alga, Heterosigma akashiwo (Raphidophyceae). J Phycol (in press)

Taylor FJR, Haigh R (1993) The ecology of fish-killing blooms of the chloromonad flagellate Heterosigma in the Strait of Georgia and adjacent waters. In: Smayda TJ, Shimizu Y (eds) Toxic phytoplankton blooms in the sea. Elsevier, Amsterdam, p 705-710

Teklemariam TA, Demeter S, Deák Z, Surányi G, Borbély G (1990) AS-1 cyanophage infection inhibits the photosynthetic electron flow of photosystem II in Synechococcus sp. PCC 6301, a cyanobacterium. FEBS Lett 270:211-215

Van Etten JL, Burbank DE, Xia Y, Meints RH (1983) Growth cycle of a virus, PBCV-1, that infects Chlorella-like algae. Virol 126:117-125

van Kooten O, Meurs C, van Loon LC (1990) Photosynthetic electron transport in tobacco leaves infected with tobacco mosaic virus. Physiol Plant 80:446-452

Watanabe M, Kohata K, Kunugi M (1987) ${ }^{31} \mathrm{P}$ nuclear magnetic resonance study of intracellular phosphate pools and polyphosphate metabolism in Heterosigma akashiwo 
(Hada) Hada (Raphidophyceae). J Phycol 23:54-62

Watanabe M, Kohata K, Kunugi M (1988) Phosphate accumulation and metabolism by Heterosigma akashiwo (Raphidophyceae) during diel vertical migration in a stratified microcosm. J Phycol 24:22-28

Waters RE, Chan AT (1982) Micromonas pusilla virus: the virus growth cycle and associated physiological events within the host cells; host range mutation. J Gen Virol 63: 199-206

Wilhelm C, Duval JC (1990) Fluorescence induction kinetics as a tool to detect a chlororespiratory activity in the

Editorial responsibility: Jed Fuhrman,

Los Angeles, California, USA prasinophycean alga, Mantoniella squamata. Biochim Biophys Acta 1016:197-202

Wilhelm SW, Suttle CA (1999) Viruses and nutrient cycles in the sea. Bioscience 49:781-788

Wolf S, Millatiner A (2000) Effect of tobacco mosaic virus movement protein on photosynthesis in transgenic tobacco plants. J Plant Physiol 156:253-258

Yamane Y, Kashino Y, Koike H, Satoh K (1997) Increases in the fluorescence $F_{\mathrm{o}}$ level and reversible inhibition of Photosystem II reaction center by high-temperature treatments in higher plants. Photosynth Res 52:57-64

Submitted: April 29, 2002; Accepted: September 26, 2002 Proofs received from author(s): January 24, 2003 